\title{
THE IMPACT OF EMPLOYEES' CRYPTO ASSET MARKET TRACKING DESIRE ON CYBERLOAFING
}

\author{
DOI: 10.17261/Pressacademia.2021.1469 \\ RJBM- V.8-ISS.4-2021(6)-p.279-290
}

\section{Inan Kaynak}

Mus Alparslan University, Malazgirt Vocational School, Malazgirt, Mus, Turkey. i.kaynak@alparslan.edu.tr , ORCID:0000-0001-9944-1540

\begin{tabular}{lll}
\hline Date Received: October 30, $2021 \quad$ Date Accepted: December 20, $2021 \quad$ OPEN OPACcEss \\
\hline
\end{tabular}

To cite this document

Kaynak, I., (2021). The impact of employees' crypto asset market tracking desire on cyberloafing. Research Journal of Business and Management (RJBM), 8(4), 279-290.

Permanent link to this document: http://doi.org/10.17261/Pressacademia.2021.1469

Copyright: Published by PressAcademia and limited licensed re-use rights only.

\section{ABSTRACT}

Purpose- In this study, it is aimed to determine whether the desire to follow the financial status of crypto assets causes cyberloafing.

Methodology- As the research method, qualitative research method was preferred. In this context, face-to-face and online interviews were conducted with 13 volunteer participants working in different sectors.

Findings- Participants; They see crypto assets among the investment tools of the future, some of the participants do not need training before investing, and they access information about the financial status of their assets from their workplace computers and personal mobile phones. In addition, it has been determined that despite the busyness of their work, the participants follow the crypto assets, that is, they show cyberloafing behavior. Another result of the study is that employees' follow-up requests regarding crypto assets continue outside of working hours.

Conclusion- As a result, it has been understood that among the precursors of cyberloafing behavior, which has serious effects on organizations, there is also the desire to follow the crypto asset market. Although many factors that cause cyberloafing have been identified, the conclusion that the follow-up request related to crypto assets may be among the premises is considered important due to its contribution to the literature.

Keywords: Crypto asset, cryptocurrency, bitcoin, loafing, cyberloafing

JEL Codes: M10, M12, C12

\section{ÇALIŞANLARDAKI KRIPTO VARLIK PIYASASI TAKIP ISTEĞININ SANAL KAYTARMAYA ETKISI}

\section{ÖZET}

Amaç - Bu çalışmada, kripto varlıkların finansal durumlarını takip isteğinin sanal kaytarmaya sebep olup olmadığının tespit edilmesi amaçlanmıştır. Metodoloji - Araştırma yöntemi olarak, nitel araştırma yöntemi tercih edilmiştir. Bu kapsamda farklı sektörlerde çalışan 13 gönüllü katılımcıyla yüz yüze ve online görüşme gerçekleştirilmiştir.

Bulgular - Katıımcılar; kripto varlıkları geleceğin yatırım araçları arasında görmekteler, katıımcıların bazısı yatırım yapmadan evvel eğitime ihtiyaç duymamakta, varlıklarının finansal durumu ile ilgili bilgilere ise iş yeri bilgisayarları ve şahsi cep telefonlarından erişmektedirler. Ayrıca, katılımcıların işlerinin yoğunluğuna rağmen kripto varlıkları ile ilgili takip yaptıkları yani sanal kaytarma davranışı gösterdikleri tespit edilmiştir. Çalışmanın diğer bir sonucu ise çalışanların mesai dışında da kripto varlıklarla ilgili takip isteklerinin devam ettiğidir.

Sonuç - Sonuç olarak örgütler üzerinde ciddi etkileri olan sanal kaytarma davranışının öncülleri arasında kripto varlık piyasası takip isteğinin de olduğu anlaşılmıştır. Sanal kaytarmaya neden olan birçok etken tespit edilmiş olmasına rağmen, kripto varlıklarla ilgili takip isteğinin de öncüller arasında olabileceği sonucu alan yazınına katkısından dolayı önemli görülmektedir.

Anahtar Kelimeler: Kripto varlık, kripto para, bitcoin, kaytarma, sanal kaytarma JEL Kodları: M10, M12, C12 


\section{GiRiş}

Para, bireylerin ihtiyaç hissettikleri ürün ve hizmetleri almada kullanılan ve binlerce yıllık geçmişse sahip bir ödeme aracıdır (Aksoy vd., 2020). Ayrıca gelecekte gelir getireceği düşüncesiyle yatırım amaçlı bir finansal varlık (Gültekin vd., 2019) olarak da kabul görmektedir. Para kavramı, tarihsel süreçte ihtiyaçların ve ticari işlemlerin dönüşümüne mukabil değişimlere uğramış ve bilgisayar teknolojilerinin gelişimiyle birlikte çeşitlenerek kripto para olarak dolaşımda yer almaya başlamıştır (Alkış, 2018). Kripto varlıkların ortaya çıkışındaki temel etken geleneksel ödeme araçlarının tüketicilerin yeni taleplerini karşılamada zorlanması olarak ifade edilmektedir (Çetinkaya, 2018). Günümüzde bitcoin ve diğer altcoinlerin günümüz ekonomik sistemlerinde ağırlığı giderek artmakta olduğundan, kripto varlıkların akademik açıdan değerlendirilmesi önem arz etmektedir (Alpago, 2018). Çok az ülkede yasal zemini olan ve buna rağmen birçok yatırımcısı bulunan kripto varlıklarla ilgili (Avşar ve Serin, 2020) araştırmaların sayısının arttığı gözlemlenmektedir (Klarin, 2020). Çalışmaların bir çoğunun halen kripto varlıklar üzerinde yoğunlaştığı (Avunduk ve Aşan, 2018) ve genellikle kavramı genel hatlarıyla açıklamaya odaklandığı görülmektedir. Kripto varlık yatırımcılarının çalışanlar üzerinde önemli etkileri olacağı, özellikle iş görenlerin kripto varlık piyasalarını takip etme dürtüsünden dolayı sanal kaytarma davranışı göstereceği düşünülmektedir.

Teknolojik gelişmelerin bireysel yaşamda olduğu kadar örgütsel yaşamda da etkileri olmuştur (Yıldırım, 2018a). Çalışanların görevlerini daha etkili ve verimli bir şeklide yerine getirmesinde yardımcı olan internetin kullanımı tüm dünyada yaygınlaşmış (Blanchard ve Henle, 2008) ve örgütlerde kullanımı kaçınılmaz bir hal almıştır (Sadıç vd., 2020). Bu olumlu yönüne rağmen iş görenlerin interneti kendi amaçları doğrultusunda kullanma eğilimi giderek artmakta (Alan, 2019) ve bu durum örgütler için bazı sorunlara sebep olmaktadır. İş yerlerinde internet kullanımın sebep olduğu sorunlar arasında zikredilen kavramlardan biride sanal kaytarmadır (Güğerçin ve Sığırcıkoğlu, 2019). İş yerinin teknolojik imkanlarını kendi ihtiyaçları doğrultusunda kullanarak örgüt için yerine getirmesi gereken çalışma faaliyetinden sanal araçlar vasıtasıyla kaytarma olarak tanımlanabilecek olan sanal kaytarma, örgütler için önemli bir sorundur. Bu sebeple alan yazınında sanal kaytarmanın etkileri ile ilgili çalışmalara rastlamak mümkündür. Sanal kaytarmanın; yenilikçi iş performansı (Semerci vd., 2021), tükenmişlik (Yıldırım, 2018a), iş tatmini (Çavuşoğlu ve Palamutçuoğlu, 2017), yabancılaşma (Babadağ, 2018), iş stresi (Özüdoğru ve Yıldırım, 2020), örgütsel özdeşleşme (Karaca ve Karaca, 2019), rol belirsizliği (Güğerçin ve Sığırcıkoğlu, 2019), sinizm (Hasırcı ve Örücü, 2020), örgütsel güven (Örücü ve Özüdoğru, 2018), sosyal dışlanma (Çiçek, 2020) ve örgüt iklimi (Özkan ve Erbay, 2021) gibi örgütsel davranış konuları temelinde öncüllerinin ve ardıllarının incelendiği görülmektedir. Fakat çalışanı sanal kaytarma davranışına iten sebepler arasında kripto varlık piyasasını takip etme isteğiyle ilgili bir çalışmaya rastlanmamıştır.

Bu çalışma birkaç amaç doğrultusunda gerçekleştirilmiştir. Öncelikle kripto varlıklara yatırım yapan çalışanların bu varlıklarla ilgili bilgi düzeyleri ölçülmeye çalışmıştır. İkinci ve en önemli amaç ise yatırımcıların bu yatırımlarıyla ilgili takip isteğinin çalışanların sanal kaytarmaya sevk edip etmediğini tespit etmektir. Sanal kaytarma davranışının hangi imkanlar kullanılarak gerçekleştirildiği ve bilgi seviyeleri ile sanal kaytarma davranışları arasında bir ilişkinin var olup olmadığının tespiti çalışmanın diğer amacıdır. Çalışma, kripto varlık yatıımcısı olan ve farklı sektörde ve görevlerde çalışan kişilerle nitel araştırma yöntemi kullanılarak yapılmıştır. Kripto varlık piyasası takip isteği ve sanal kaytarma davranışı değişkenlerini ele alan başkaca bir çalışmaya rastlanılamadığından, çalışmanın alan yazınına katkı sunacağı düşünülmektedir.

\section{KRIPTO VARLIK}

Tarihi insanlık tarihi kadar eski olduğu düşünülen (Şenbayram, 2019) ve bir mübadele aracı olarak tanımlanan paranın genel kabul görmüş bu tanımı her geçen gün değişen koşullardan dolayı güncellenmektedir (Çetinkaya, 2018). Önceleri üretildiği maden değeri ile kabul gören para, günümüzde somut bir varlıktan sıyrılarak sanal bir değişim aracına dönüşmüştür (Alkış, 2018). Para birçok işlevi olmakla birlikte tasarruf aracı olma fonksiyonuna da sahiptir. Insanlar ellerindeki atıl olarak nitelendirilebilecek parayı gelir getirici bazı enstrümanlarda da değerlendire bilmektedirler. Bu yatırım enstrümanlarından biride son yıllarda oldukça popüler olan (Aksoy vd., 2020) ve 2008 yılı küresel kriz sonrası ortaya çıkan "defacto" mali araçlar olarak nitelendirilen kripto paralardır (Arıkan, 2020).

Kripto para; kelime anlamı şifreli para olan ve yalnızca sanal ortamlarda bulunan (Turan, 2018), kişiden kişiye para transferine imkan sağlayan, dünyada herhangi bir ülkeye veya otoriteye bağlı olmayan para sistemdir (Uçkun ve Dal, 2021). Kripto varlıklar, kriptoloji temelli blok zincir olarak nitelendirilen bir yapı kullanılarak oluşturulur (Şahin, 2018). Kripto analiz ve kriptografi şeklinde iki unsur içeren kriptoloji, verilerin yüksek güvenirlikli bir ortamda şifrelenip alıcıya iletildiği ve deşifre edildiği sistemdir (Yılmaz, 2007). Kripto varlıklar, blokchain temelli varlıklardır (Nakamoto, 2008). Blokchain, verilerin saklanması ve daha sonra ulaşıımasına imkân sağlayan, sisteme kayıtlı kullanıcıların verilerinin doğruluğunu karşılıklı mutabakat yoluyla sağladığı ve bu şekilde sisteme yeni blokların eklendiği veri zinciridir. Bloktaki her halka kendinden önceki işlemin bir özetini içermektedir. Bu özet, dışarıdan müdahale ile 
değiştirilmenin önüne geçilmesini sağlar (Yalçın, 2019). Blockchain sisteminin en bilinen uygulamalarından biri sanal para oluşturma işlemlerinin sağlandığı kripto para madenciliğidir (Şahin, 2019). Yüksek işlemci gücüne sahip bilgisayar donanımları aracılığıyla sanal paranın oluşturulmasından dolayı bu işleme madencilik (hardware mining) denilmektedir (Alpago, 2018). Blockchain sayesinde bireyler madencilik faaliyeti veya coin transferi yoluyla kendi kripto paralarını edinebilmekte ve kripto cüzdan olarak nitelendirilen şahsi hesaplarında tutabilmektedirler (Özdemir, 2021). İlk olarak 2008 yılında üretilmeye başlayan kripto paralar (Yıldırım, 2018b), Bitcoin, Altcoin ve Tokenları kapsamaktadır. Kendine ait Blockchain'ini kullananlar “Coin” olarak adlandırılırken, başka bir Coin'in Blockchain' ini kullananlar ise Token olarak adlandırılmaktadır (Bilgili ve Cengil, 2019). Bitcoin'in zamanla yoğun ilgi görmesi ve üretiminin zorlaşması nedeniyle (Kaplanhan, 2018), bitcoin alternatifi olabilecek kripto varlık arayışına girişilmiş ve geliştirilen bu varlıklar, bitcoin'e alternatif olarak geliştirildiğinden "Alternatif Coin” anlamın gelen "Altcoin” olarak adlandırılmıştır (Ateş, 2016). Kripto paralara bakış açısı, yasal statüsü ve kullanılabilirliği, ülkeden ülkeye değişiklik gösterse de (Aksoy vd., 2020), değişim aracı olarak alış verişte kullanılmakta (Ateş, 2016), alım ve satıma konu olmakta ve yatırım aracı olarak ta kullanılmaktadır (Aslan, 2020). Kripto varlıkların bir yatııım aracı olarak görülmesinin temel nedeni fiyatlarındaki volatiliteden (Buğan, 2021), yani belirli bir zaman aralığındaki "oynaklığından” kaynaklandığı söylenebilir. Bu volatilite kripto yatırımcılarının kar elde etmeleri için kripto para piyasalarını sıklıkla takip etmelerine sebep olabilmektedir. Kripto varlıklarla ilgili bilgilere ulaşma isteği mesai saatleri içinde de olabileceğinden çalışanlarda sanal kaytarma davranışı oluşabilecektir.

\section{SANAL KAYTARMA}

Modern zamanlar olarak ifade edilen günümüzde, bir işyerlerinin bilgisayar ve internetsiz olması neredeyse imkansızdır (Baturay ve Toker, 2015). Bu gereklilik çalışanların mesai saatleri içerisinde iş yerinin imkanlarını kendi özel işleri için kullanmalarına sebep olabilmektedir (Yıldız vd., 2016). Çalışanlarda sapkınlık davranışı olarak adlandırılan (Seçilmiş ve Yılmaz, 2018) ve yüksek tirajlı gazetelerin yazılarının etkisiyle alan yazınına kazandırılan sanal kaytarma kavramı (Karataş ve Avci, 2017), iş görenlerin interneti kendi ihtiyaçları için kullanma yönelimlerini açıklamak için kullanılmıştır.

Milenyum çağıyla birlikte tam anlamıyla ortaya çıkmaya başlayan sanal kaytarma (Sadıç vd., 2020), "siber kaytarma", "siber aylaklık" ve "sanal sapkınlık" gibi farklı adlar altında alan yazınında araştırmalara konu olmuştur (Akbaba, 2009; Demirbilek ve Atila, 2021). Bu durum kavramın tanımlanmasına da yansımıştır (Özüdoğru ve Yıldırım, 2020). Jonhson ve Indvik (2003) kavramı; iş yerinin imkanlarını kullanarak, çalışma zamanını boşa harcayacak aktiviteler, Robinson ve Bennett (1995), işle ilgisi olmayan davranışlar neticesinde örgüt kaynaklarının gereksiz ve boş yere kullanılması, Ugrin vd. (2008) çalışanın zamanını internette verimsiz harcaması, Kim ve Byrne (2011) örgütün sağlamış olduğu internet imkanını veya şahsi cep telefonlarını işle ilgisi olmayacak şekilde kullanmaları, Anandarajan ve Simmers (2004) mesai saatleri içinde yapılan gönüllü ve kişisel amaçlar doğrultusunda gerçekleşen davranış (Prasad vd., 2010) şeklinde tanımlamışlardır. Yapılan bu tanımlarda genellikle kaytarma davranışının örgüt imkanlarıyla gerçekleştirildiği ifade edilse de günümüz teknolojik imkanları kişilerin kendi imkanlarını kullanarak ta kaytarma yapabilmesine olanak sağlamaktadır. Bu durumdan hareketle Çiçek (2020) sanal kaytarmayı; "Çalışanın hem örgütün alt yapısını hem de bireysel imkanları kullanarak iş yerinde tüm iletişim vasıtalarıyla yaptığı kaytarmaların tümü" olarak tanımlamaktadır. Tüm bu tanımlardan hareketle bir davranışın sanal kaytarma davranışı olabilmesi için, işyerinin imkanları ya da kendi mobil cihazlarıyla yapılması, çalışma saatleri içinde gerçekleşmesi, kişisel amaçlar doğrultusunda gerçekleştirilmesi, çalışanın özgür iradesiyle yapılması, üretim ve performans kaybına sebep olması koşullarını taşıması gerekmektedir (Tutar ve Güler, 2020). Sanal kaytarmanın iş hayatında bazı olumsuzluklara neden olduğu bilinmektedir (Çetin ve Akyelli, 2020). Mills vd.'leri (2001) ne göre sanal kaytarma, verimlilik kaybı ve finansal zarar, örgüt kaynaklarının aşırı kullanımı ve yasal sorumluluk olmak üzere örgütlerde üç ana soruna neden olmaktadır. Bunlardan ilki olan verimlilik kaybı ve finansal zarar çalışanın işiyle uğraşması gerekirken başka şeylerle uğraşının sonucu olarak meydana gelmektedir. İkinci sorun örgüt kaynaklarının aşııı kullanımıdır ki bu durum hem cihazlara zarar verebilmekte hem de iş yerinin internet ağında yoğunluğa sebep olarak diğer işlerin aksamasına sebep olabilmektedir. Sonuncu ise yasal olmayan bazı sitelere çalışanın girmesi, işletmeyi bazı hukuki zorluklarla karşı karşıya bırakabilecektir (Çetintürk, 2020). Cinsel taciz içeren sitelere girme, sanal zorbalık yapma veya kumar oynama örgütün ciddi yasal sorunlarla uğraşmasına neden olabilecektir (Piotrowski, 2012). Sanal kaytarma, iş görenler açısından ise işleri yetiştirememe, şahsi bilgilerin çalınması, odaklanamama, terfi almama ve diğer olanaklardan istifade edememe, disiplin cezası alma ve işten çıkarılma gibi bazı olumsuzluklara sebep olabilmektedir (Öztürk, 2015). Örgüte ve çalışanlara zararları olan sanal kaytarmanın bazı olumlu taraflarının da olduğu ifade edilmektedir (Örücü ve Yıldız, 2014). Anandarajan vd.'leri (2011) kaytarma davranışının kısa süreli dinlenmeye imkan sağladığı için çalışan performansında ve verimliliğinde artış sağlayabileceğini, Blanchard ve Henle (2008) ise çalışanların öğrenme ve inceleme fırsatını bu sayede yakalayarak yaratıcılıklarının artabileceğini savunmuşlardır. Sanal kaytarma davranışının oluşumu bazı faktörlerle ilişkilidir. Van Doorn (2001) bu faktörleri kişisel ve örgütsel faktörler olarak gruplandırmıştır. Kişisel faktörler; alışkanlıklar, algı ve tutumlar, internet bağımlılı̆ı düzeyi, demografik ve kişisel özelliklerdir (Çınar ve Sıçrar, 2019). Jia vd.'leri (2013), çalışmalarında kaytarma davranışının demografik faktörlerle ilişkili 
olduğunu tespit etmişlerdir. Örgütsel faktörler ise kaytarma davranışının çalışanlar tarafından algılanması, internet kullanımının kısıtlanması, yönetimsel destek ve çalışanların işleriyle ilgili tutumlarıdır (Çınar ve Sıçrar, 2019). Ayrıca Garrett ve Danziger (2008), işyerindeki otonomi düzeyi, mesleki durum ve gelir düzeyinin kaytarma davranışının önemli göstergelerinden olduğunu belirtmiştir. Gelir düzeyi diğer birçok davranışı etkilediği gibi çalışanların sanal kaytarma davranışı göstermesini de etkileyebilmektedir. Nitekim Blanchard ve Henle (2008), finans sitelerinde gezinmenin de bir kaytarma davranışı olduğunu belirtmektedir. Tüm bu bilgiler ışığında çalışanların gelirlerini arttırmak, tasarruflarının durumu incelemek ya da yüksek volatiliteye sahip kripto para piyasalarından gelir elde edebilmek amacıyla sanal kaytarma davranışı gösterebileceği düşünülmektedir.

\section{YÖNTEM}

Çalışmanın amacı, kullanımı her geçen gün artan kripto varlıkların (Ateş, 2016) finansal durumlarıyla ilgili takip isteğinin sanal kaytarma davranışıyla ilişkili olup olmadığını ortaya koymaktır. Çalışma kapsamında verilerin toplanmasından önce, T.C. Muş Alparslan Üniversitesi Rektörlüğü Bilimsel Araştırma ve Yayın Etiği Kuruluna, 01.09.2021 tarihinde talepte bulunulmuş ve araştırma yapma izni alınmıştır. Bu kapsamda, zengin ve detaylı bilginin alınmasına imkân vermesinden (Yıldırım ve Şimşek, 2006) dolayı araştırmada amaçı̈ı örneklem modeli kullanılmıştır. Yani örneklem finansal yatırım araçları içinde kripto varlıkları da bulunan çalışanlardır. Fakat bu çalışanlara bir veya birkaç örgütte ulaşmanın güç olacağı ve ulaşılan kişilerin araştırmaya katılmayabileceği düşüncesiyle, akıllı telefonlarda kullanılan anlık mesajlaşma uygulamalarının durum bölümüne çalışma ile ilgili kısa bilgi konarak gönüllü katılımcı aranmıştır. Bu yöntemle 13 katılımcıdan olumlu geri dönüş alınmıştır. Araştırmanın ana amaçlarından biri olan sanal kaytarma davranışının var olup olmadığının tespitinin derinlemesine sorular sorularak elde edilebileceği düşüncesinden hareketle, nitel araştırma yöntemi belirlenmiştir.

Nitel çalışmalarda örneklem büyüklüklerinin kabul edilebilir düzeyde olması ve inandırıcılığının kanıtlanabilmesi çalışmanın kalitesini arttırmaktadır. Ayrıca ulaşılan verilerin geçerlik ve güvenirlikleri de önem arz etmektedir (Başkale, 2016). Nastasi (2015), nitel çalışmalarda örneklem büyüklüğünün belirlenmesinin kullanılan yönteme göre seçilmesi gerektiğini ve anahtar bilgi olarak nitelendirilen araştırmalarda 5 katılımcının olmasının yeterli olacağını ifade etmiştir. Çalışmada amaçlı örneklem yönteminin belirlenmesi ve ulaşılan verilerde anahtar bilginin katılımcıların kripto varlıkların piyasasıyla ilgili takip isteğinin sanal kaytarmaya olan etkisi olduğundan örneklemin beş ve üzeri kişi olması yeterli kabul edilmiştir.

Nitel araştırmalarda geçerlilik ve güvenilirlik nicel araştırmalardan farklı biçimde ele alınır (Yıldırım ve Şimşek, 2013). Guba ve Lincoln (1982), nitel çalışmalarda geçerlik-güvenilirlikten ziyade inandırıcılığın olması gerektiğini, inandırıcırlığın; inanıırlık, onaylanabilirlik, güvenilebilirlik ve aktarılabilirlik olmak üzere dört ilke ile açıklanabileceğini ve nitel araştırmanın doğruluğunun bu ilkelerden bir veya birkaçının uygulanması ile sağlanabileceğini ifade etmişlerdir (Creswell, 2003). Holloway ve Wheeler (1996), inanılırlığı artırmak için; uzun sürecek bir etkileşim, katılımcı teyitleşmesi ve uzman incelemesi gibi yöntemlerin olduğunu ifade etmişlerdir. Uzun süreli etkileşim araştırmacının ön yargılarından kurtulmasına yardımcı olacağı gibi Streubert ve Carpenter (2011) bu sayede doğru ve eksiksiz yanıtlar alınmasının mümkün olacağını belirtmişlerdir. Bu kapsamda çalışmada geçerlilik ve güvenilirlik yerine kullanılacak yöntem olan inanırlılığı arttırmak için gönüllü olan katılımcılarla yüz yüze görüşmeler yapılması planlanmıştır. Gönüllü olan katılımcılardan bazılarının koronavirüs (Covid 19) tedbirleri kapsamında yüz yüze görüşmeyi kabul etmemesi ve bazı katılımcılarında araştırma yapılan ilde bulunmamasından dolayı görüşmelerin bir kısmı online görüşme imkânı sağlayan araçlar (programlar) vasıtasıyla yüz yüze gerçekleştirilmiştir. Bu görüşmelerde katılımcıların yaş, cinsiyet ve mesleki bilgi ve çalışma sürelerini içeren demografik veriler elde edilmiştir. Ayrıca, kripto varlıklarla ilgili bilgi, bu varlıklara olan güven düzeyi ile yatırım öncesi karar vermelerine yardımcı olabilecek herhangi bir eğitim alıp almadıkları bilgisi elde edilmeye çalışımıştır. Son olarak yatırımlarının seyrini hangi araçlar vasıtasıyla öğrendikleri, bu araçları hangi sıklıkla kullandıkları, iş dışında iken yatırımlarını nasıl takip ettikleri ve ne kadar süre harcadıkları öğrenilmeye çalışılmıştır. İşlerinin yoğunluğunu değerlendirmelerini istediğimiz son soru ile katılımcıların iş yoğunluğunun seviyesi ölçülmeye çalışılmıştır. Çalışmaya katılan kişiler gönüllü katılımcı "GK" olarak kategorize edilmiş ve gönüllü katılımcılarla ilgili demografik veriler tablo $1^{\prime}$ de verilmiştir.

Tablo 1: Katılımcı Bilgileri

\begin{tabular}{lllll}
\hline Katılımcılar & Yaş & Cinsiyet & Meslek & TÇS* \\
\hline GK1 & 48 & Erkek & Memur & 20 \\
\hline GK2 & 37 & Erkek & Akademisyen & 13 \\
\hline GK3 & 29 & Erkek & Akademisyen & 3 \\
\hline
\end{tabular}




\begin{tabular}{lllll}
\hline GK4 & 48 & Erkek & Mali Müşavir & 21 \\
\hline GK5 & 41 & Erkek & Mühendis & 20 \\
\hline GK6 & 39 & Erkek & İşçi & 20 \\
\hline GK7 & 20 & Erkek & İ̧̧ geliştirme stajyeri & 1 \\
\hline GK8 & 35 & Erkek & Akademisyen & 10 \\
\hline GK9 & 34 & Elektrik Elektronik Mühendisi & 10 \\
\hline GK10 & 35 & Memur & 8 \\
\hline GK11 & Erkek & Satın alma müdürü & 5 \\
\hline GK12 & 28 & Erkek & Mühendis & 15 \\
\hline GK13 & 40 & Erkek & Memur & 5 \\
\hline TÇS: Toplam Çalışma Süresi (Yıl) & Erkek & & \\
\hline
\end{tabular}

Tablo 1'den de anlaşılacağı üzere çalışmaya 13 gönüllü katılmıştır. Katılımcıların tamamı erkektir. Katılımcıların en genci 20 , en yaşlısı ise 49 yaşındadır. Katılımcıların çoğu 30'lu yaşlardadır. Kıdem olarak da adlandıılan toplam çalışma süresi 1 yıl ile 20 yıl arasında değişmektedir. Katılımcıların mesleklerine bakıldığı zamanda farklı meslek gruplarından olduğu anlaşımaktadır. Bu sonuçlar kripto varlık yatırımcılarının farklı yaşlarda, farklı kıdemlerde ve farklı mesleklerde olabileceği anlamına gelebilir.

\section{BULGULAR}

Araştırmaya katkı sunan katılımcılar GK1 ile GK13 arasında kodlanmıştır. Katılımcılarla ön görüşmeler yapılarak müsait oldukları tarih ve zaman dilimleri öğrenilmiş ve bu tarih ve zamanda katılımcıların ofislerinde yüz yüze görüşmeler yapılarak kayda alınmıştır. Katılımcılarla ofislerinde görüşme kendilerini daha rahat hissedecekleri düşüncesiyle gerçekleştirilmiştir. GK11 ve GK9 çalışmanın yapıldığı ilin dışında olması ve GK3'ün ise koronavirüs önlemleri çerçevesinde online görüşme isteği üzerine üç katılımcı ile online görüşme gerçekleştirilmiştir. Gönüllü katılımcılara 4'ü demografik ve 8'i açık uçlu olmak üzere toplamda 12 soru yöneltilmiştir. Görüşmeler kayıt altına alınarak daha sonra yazıya dökülmüştür. Yapılan görüşmeler neticesinde gönüllü katılımcıların açık uçlu sorulara verdiği cevaplardan "evet", "hayır", fikrim yok" gibi kısa cevaplar çıkarıldıktan sonra kalanlar aşağıda verilmiştir.

\section{S5. Kripto varlıkları nasıl tanımlarsınız?}

\section{GK1: Yatırım aracı}

GK2: Paranın geleceği olarak tanımlanabilir. Günümüzde dijitalleşmeye müsait her metanın yerini dijital alternatiflere bıraktığını görüyoruz, bu durumun para için olan karşıığının kripto varlıklar olacağını yakın gelecekte hepimiz göreceğiz. Cebimizde bozuk para aramak yerine telefonlarımızı tokuşturarak alışveriş yapabileceğiz. Pandemi sürecinde nasıl ki kredi kartıyla temassız işlem yapma yaygınlaştıysa, belirli bir kırılma noktasından sonra kripto varlıkların da bu şekilde yayılacağına inanıyorum.

\section{GK3: Yatırım aracı (spekülasyona açık)}

GK4: Kripto para, güvenli işlem yapmak amacıyla şifreleme (kriptografi) kullanan, çalışma şekli nakitin alternatif olarak düşünülmüş bir dijital varlıktır. Mevcut bankacılık sistemlerinden farklı olarak bir merkezde toplanmaz yani merkeziyetsizdirler. Bunun temin edilmesi ise blok zincir (Blockchain) olarak adlandırılan sistemden gelmektedir.

\section{GK5: Şifrelenmiş merkeziyetsiz finansal sanal varlık}

GK6: Hayali para

GK7: Blockchain teknolojisi kullanılarak oluşturulan ve geleceğin ödeme sistemlerinde büyük rol oynaması beklenen yüksek güvenlikli bir teknoloji.

GK8: Blokzincir teknoloji kullanan finansal yapılar.

GK9: Dijital Para. Madencilik ile üretilen. 
GK10: Piyasadaki arz miktarı genelde sınırsız ve kaynağı belli olmayan varlık

GK11: Blockchain tabanlı sanal para birimi

GK12: Riskli volatilitesi yüksek sayısal veriler

GK13: Dijital para yerine geçen kıymetli varlık

Kripto varlıklarla ilgili katılımcıların bilgi düzeyini ölçmeye çalışılan bu sorunun cevaplarından da anlaşılacağı üzere GK1, GK3 ve GK6 nolu katılımcıların cevaplarının kısa ve çok açıklayıcı olmadığı anlaşılmaktadır. Bu durum katılımcıların çoğunun kripto varlıklarla ilgili çok fazla bilgi birikimine sahip olmadığı anlamına gelebilir. Fakat bu katılımcıların cevaplarının ortak noktasının kripto varlıkları finansal bir varlık olarak kabul ettikleri ve bir yatırım aracı olarak gördükleridir. GK2, GK4 ve GK7 nolu katılımcıların diğerlerinin aksine kripto varlıklarla ilgili bilgi sahibi oldukları ve bu varlıkların gelecekteki konumu ve kullanımıyla ilgili tahminlerinin olduğu görülmektedir.

\section{S6. Kripto varlıklar sizce güvenilir bir yatırım aracı mıdır, neden?}

GK2: Bu soruya cevap verebilmek için öncelikle "kripto varlık" kavramını iyi irdelemek gerektiğini düşünüyorum. Marketteki tüm coin ve tokenları kripto varlık olarak görüp tamamı güvenilir veya güvenilmez diye yaftalamayı uygun bulmuyorum. "Para güvenilir mi?" sorusuna cevap vermek gibi bir durum söz konusu oluyor. Para deyince Amerikan doları da Moritanya Ugiyası da akla gelebilir. Nasıl ki her ikisi eşdeğer güvenilirlikte değilse aynı durum kripto varlıklar için de geçerlidir. Dolar kadar güvenilir coinler olduğu gibi Ugiya kadar güvenilmez tokenlar da var. Tabi burada yatırımdan ne anladığımıza da bakmalıyız. Maddi varlığımızı alıp rahatça dolaşalım veya transfer edelim diyorsak eğer kripto varlıklar oldukça güvenilir bir metot buna karşın manipülasyona oldukça açık, ciddi sert hareketlerin göründüğü, 24 saatin oldukça önemli bir zaman dilimi olduğu, öngörünün kısıtlı olduğu bir pazardan bahsediyoruz. Yatırımcısı buna göre kendi doğruları içerisinde "güvenilir" değerlendirmesi yapmalıdır.

GK3: Spekülasyona açık olduğundan dolayı çok güvenilir olduğunu düşünmüyorum.

GK4: Temel, teknik ve Onchain ve Sentiment analizleri beraber kullanıldığı takdirde risklerin minimize edilebileceği yatırım aracıdır diyebilirim. İstisnai durumları da vardır en büyük risk almış olduğunuz coinin borsadan delist edilmesidir. Tüm bu koşullara rağmen bütün para piyasalarına oranla daha riskli ve daha kazançlı ayırımını da unutmamak gerekir.

GK5: Kripto cüzdan şifrenizi unutmadığınız sürece güvenlidir.

GK6: Çok güvenli değil

GK7: Kripto paralar düşünce ve teknoloji olarak bence inanılmaz bir potansiyele sahip ancak günümüzde sıkça karşılaştığımız platform ve insanlardan kaynaklı kötü kullanımlar sebebiyle güven konusunda sorunlar oluşabiliyor. Prosedür ve hukuki süreçlerin daha net ve kötüye kullanılamaz hale gelmesi gerekir. Bir yandan da Elon Musk gibi devlerin buradaki büyük etkisi beni kripto paradan soğutuyor.

GK8: Kısmen güvenilir. Manüplasyona açık bir yapısı olsa da uzun vade yatırım için değerlendirilebilir.

GK9: Hayır. Kontrolsüzdür.

GK10: Hayır. Kripto varlığın sahibi üretimi devlet kontrolünde olmadıkça güvenilir değil

GK11: Bence güvenilirdir. Merkeziyetsiz ve blockchain tabanlı oluşu benim için yeterli bir güven sebebi.

GK12: Riskli araçlardır. Sayısal şifreler kaybolursa veya bağlı bulunduğu protokol sonlanırsa kazançlar sıfırlanır.

GK13: Tam emin olmamak ile birlikte geleceğin para birimi olacağına güvencim bulunmakta.

Kripto varlıkların güvenilirliği ile ilgili bu soruda katılımcıların bazılarının güvenilir olmadığı ile ilgili net bir fikirde olduğu, bazılarını ise yine aynı netlikte güvenilir bulduğu anlaşılmaktadır. Bazı katılımcıların ise çok kesin cevaplardan kaçınarak riskli bulduğu görülmektedir. Bu risk kaynağının ise kripto varlığın kendisinden kaynaklanmadığı kötü niyetli kullanıcılardan dolayı risk oluşturduğu verilen cevaplardan anlaşılmaktadır. Ayrıca bu varlıklara yatırım yapan zengin kişilerin spekülatif davranabileceği bu sebeple risk intiva ettiği de verilen cevaplardan ulaşılan sonuçlar arasındadır. Diğer bir sonuç ise, güvenilir olmayan fiziki paralar olduğu gibi güvenilir olmayan kripto varlıklarında olabileceğidir. Bu sebeple kripto varlık yatırımcıların seçici davranması gerektiği verilen cevaplardan anlaşılmaktadır. 


\section{S7. Herhangi bir kişi kripto varlıklara neden yatırım yapmalıdır?}

GK1: Kısa zamanda yüksek gelir elde edilebilir

GK2: Daha önce de belirttiğim gibi öncelikle kripto piyasasını paranın geleceği olarak görüyorum. Bu önlemli bir yatırım sebebidir. Bunun yanı sıra piyasadaki tüm yatırım araçları düşünüldüğünde en yenisinin kripto piyasası olduğunu söyleyebiliriz. Bu da fırsatların en yoğun olduğu piyasa anlamına gelmektedir. Yanı "babalarımız zamanında şuradan bir arsa alsaydı şimdi zengindik" diye içimizden geçirdiğimiz şeylerin yerine 20 yıl sonra çocuklarımız "babam şu coini alsaydı simdi zengindik" diyerek hayıflanacakları kanaatindeyim. Bu nedenle yatırım için uygun bir mecra olduğunu söyleyebilirim.

GK3: Kar elde etmek için yatırım yapmalıdır

GK4: Herhangi bir kişi kripto para piyasasında işlem yapmamalıdır :))). Para piyasalarını global ve makro anlamda tüm kıymetlerle beraber değerlendirme bilgisine sahip, takip gerçekliğinin farkında olan kişiler yatırım yapmalıdır. Örnek olarak dolar ve altındaki ani değişiklik diğer piyasaları ne kadar etkiliyor ise volatilesi daha yüksek olan kripto dünyasını fazlasıyla etkilemektedir. Kar ve zarar oranları da buna göre değişiklik gösterir. İşin tüm alanlarına hakim olsanız dahi 10 işlemden 6 işlemin başarılı olması bu piyasa için yeterli rantabileteyi sağlayacaktır.

GK5: Yatırım alanlarını farklılaştırmak için.

GK7: Çevresindeki yayılan kriptodan kazanma hikayeleri sebebiyle yatırım yapma ihtimali yüksek. Altın ve dolar gibi yatırım araçlarına göre çok daha hızlı kazanma ihtimali kriptoyu ilgi çekici kılıyor.

GK8: Kısa zamanda yüksek kazanç için.

GK9: Yapılmamalıdır. Fazla agresiftir.

GK10: Anlık artış oranının yüksekliği ve sınırsızlığı cazibeli hale getiriyor

GK11: Kripto varlıklar bir start up a yatırım yapmak gibidir. Sizi bir gecede milyoner yapabilirken aynı şekilde paranızın çöp olmasına da sebep olabilir. Sanırım ilk seçenek yatırım yapmak için yeterli bir sebep :)

GK12: Dijital çağa ayak uydurmak ve yüksek risk yüksek kazanç sağlamak için.

GK13: Oldukça yüksek kazançlar sağlama ortamı ve fırsatı yaratmakta.

Kripto varlık yatırımcısı çalışanların bu alana başkaları da yatırım yapılmalı sorusuna verilen cevapların (GK9 Hariç) tamamı yapılması gerektiği yönündedir. Cevapların genelinden kripto varlıklardaki riskin yüksekliğini kazancın yüksekliğiyle eşdeğer kabul ettikleri, bazı katılımcılar ise gelecekte yatırım yapılmamasından dolayı pişmanlık duyulacağını ifade etmişlerdir. Tüm bu cevapların neticesinde katılımcıların herhangi bir kişinin kripto varlıklara yatırım yapması gerektiği fikrinde oldukları sonucuna varılabilir.

\section{S8. Kripto varlık piyasasına girmeden önce bu alanla ilgili bir eğitime ihtiyaç hissettiniz mi, neden?}

GK2: Tabi eğitimin önemli olduğunu düşünüyorum. Nedeni okula neden gidiyoruz sorusunun cevabıyla aynı aslında. Eğitim bilmediğimizi öğrenmek demektir. Bu ise girmeden önce bilmiyordum ve eğitime tabiki ihtiyaç duydum. Buna karşın girdiğim dönemde eğitim fırsatı olmadığı için eğitim almak gibi bir şansım olmadı. Zor yoldan yaparak öğrenmek durumunda kaldım.

GK3: Daha bilinçli hareket etmek için teknik analiz konusunda eğitime ihtiyaç duyulabilir

GK4: Kesinlikle evet, piyasaya hâkim değilseniz kaybetmeye mahkûm olursunuz. Ekonomi piyasalarına hâkim değilseniz kripto dünyasıyla vedalaşmak daha faydalı olacaktır Tüm likit varlığınızı kaybedersiniz.

GK5: Girmeden önce değil ama girdikten sonra hissediyorum.

GK6: Hissettim.

GK7: Hissettim çünkü bilmeden yapıldığında büyük sorunlara yol açabilir bu sebeple kripto paraları kullananların grafik okuma gibi temel eğitimleri alması gerekir.

GK8: Hissetmedim. liçine girdikçe öğreniliyor.

GK9: Hayır. Kurallar gayet açık.

GK10: Evet. Bilinmeyen ortamda daha fazla nasıl kazanç elde edilir yatırımın hangi tokene yapılması gibi. 
GK11: Kesinlikle eğitim alınmalıdır. Ne olduğunu bilmediğimiz bir şeye yatırım yapmak hatadır. Temel ve teknik analiz bilgisi doğru kripto varlığa hatta diğer tüm yatıım araçlarına doğru şekilde yatırım yapmanızı sağlar.

Bu sorunun cevaplarından da anlaşılacağı üzere katılımcılar kripto varlık piyasasına yatırım yapmadan evvel eğitim alınıp alınmaması ile ilgili farklı görüşleri vardır. Eğitimin gerekliliğini savunan kullanıcıların bu gerekliliği temellendirdiği ve neden gerekli olduğunu açıkladığı anlaşılmaktadır. Eğitime intiyaç hissetmediğini beyan eden katılımcıların ise cevaplarının çok kısa ve neden gerekli olmadığıyla ilgili bir açıklamalarının olmadığı görülmektedir.

\section{S9. İş yerinizde iken kripto varlıklarla ilgili alım satım işlemlerinizi yapmak için hangi araçlara ihtiyaç duymaktasınız?}

GK1: Telefon.

GK2: Kripto piyasası sürekli bir piyasa olduğu için takip etmem gerekiyor. İşyerinde bunu genellikle cep telefonum aracılığıla yapıyorum. Yatırım kararı almak için daha fazla teknik analiz yapmam gerektiğinden bilgisayara ihtiyacım oluyor ama bunu genellikle işyerinde yapmamaya çalışıorum.

GK3: Cep telefonu ve bilgisayar.

GK4: Her ikisini de kullanmaktayım, ancak önceliğim kendi işim. Bilgisayarla grafik incelemeleri daha rahat, telefonla anlık takip ve işlem yapmak daha rahat.

GK5: Cep telefonu.

GK6: Cep telefonu.

GK7: Kripto paralarla ilgilenirken bilgisayarların grafiklerin detaylı ve uzun vadeli okunabilesi adına önem arz ediyor. Ancak kriptonun en önemli özelliklerinden olan kolay ulaşılabilirliği onu telefona da bağlı kılıyor. Tablet üzerinde kullanmadım ve kullananla da hiç karşılaşmadım.

GK8: Cep telefonu kullanıyorum. Rahat ve kullanışlı olduğu için.

GK9: ihtiyaç duymadım.

GK10: Bilgisayar ve cep telefonu.

GK11: Bilgisayar ve telefon ama bilgisayar kesinlikle şart.

GK12: Cep telefonu.

GK13: Bilgisayar oldukça hız sağlamakta ama telefon ile de rahatlıkla işlemlerinizi gerçekleştirebilmektesiniz.

Katılımcıların cevaplarından kripto varlıkların takip, alım ve satım işlemlerinin genellikle cep telefonu üzerinden yapıldığı anlaşılmaktadır. Bazı katılımcılar cep telefonunun yanı sıra bilgisayarları da kullandıklarını ifade etmişlerdir. Bazıları ise varlıkların analizi için telefonun yeterli olmamasından dolayı bilgisayara ihtiyaç hissettiklerini ifade etmiştir. Tüm bu cevaplardan katılımcıların hepsinin (GK9 hariç) işyerinde cep telefonu veya bilgisayardan kripto varlıklarıyla ilgili işlemler yaptığı anlaşılmaktadır.

S10. Gün içinde kripto varlık piyasasının güncel durumunu kontrol edebilmek için bilgisayara hangi sıklıkla bakmak zorunda kalıyorsunuz ve sizce toplamda ne kadar bir süre harcıyorsunuz?

GK1: 2-3 saatte bir.

GK2: Bilgisayardan ziyade telefonum üzerinden kontrol ediyorum piyasayı. Bu durum piyasanın hızına göre değişebiliyor. Ortalama bir günde 15-20 dakika yeterken hareketli bir günde 4 saate kadar takip etmek zorunda kalabiliyorum.

GK3: Günde birkaç kere bakıyorum ve toplamda 15 dakika civarı harcıyorum.

GK4: Iş̧imde boş zamanlarda bakıyorum, evde ise daha çok ailemle vakit geçiriyorum. Sitemin kendi kendine işlediği alarm, alım satım emirleri olduğu için uzun uzun vakit harcamıorum. Ortalama 3 saat olabilir.

GK5: Cep telefonundan 30 dakika, PC den hiç bakmıyorum.

GK6: Çok sık değil ara ara. Günde bir iki saat.

GK 7: Kripto paralar işlem yapma konusunda tüm güne müsaade ettiği için insanlar uzun süreler akşamları işten gelince özellikle uzun 
zamanlar harcıyor. Ben sabah ve akşamları özellikle çok fazla bakıyorum gün içerisinde de 1 dakikalık kısa periyotlarla çok fazla bakıyorum. Toplamda 12 saatimi alıyor.

GK10: Yatırım yaptığım dönemde zamanın birçoğunu kontrol ederek harcarım.

GK11: Bu sizin yatırım aracınızın vadesiyle alakalı. Kısa vadeli yatıım için PC başından kalkmak genelde mümkün olmuyor. Ama genel tabiriyle minimum 56 saatimi veriyorum.

GK13: Her saat başı çünkü anlık olarak her şey değişebilmekte.

Çalışanlarda iş yerinde kendi cihazları veya iş yerinin bilgisayarlarıyla kripto varlıkların durumu hakkında bilgi edindikleri bir önceki sorunun cevaplarından anlaşılmıştı. Bu soruda ise çalışanların vaktinin ne kadarını kripto varlık yatırımlarını izlemek için harcadığı ölçülmeye çalışılmıştır. Verilen cevaplardan anlaşıldığına göre GK9 ve GK11 gün içinde kripto varlıklarının finansal durumunu öğrenme ile ilgili bir sanal kaytarma davranışı göstermedikleri, fakat geriye kalan 11 katılımcının gün içinde yarım saatten az olmamak koşuluyla saatlerce bu varlıkların finansal durumlarını takip ettikleri yani sanal kaytarma davranışı gösterdikleri anlaşılmaktadır.

S11. İ̧ yerinizde olmadığınız zamanlarda kripto varlıklarla ilgili alım satım işlemleri yapıyorsanız bu işlemleri hangi cihazlardan (Bilgisayar, tablet, Cep telefonu) yapıp ne kadar bir süre harcıyorsunuz?

GK1: Telefon.

GK2: Iş̧ dışında genellikle bilgisayar üzerinden piyasayı takip ediyorum. Bu sürede yatırım kararları da verdiğim için daha detaylı bir inceleme yapmam gerekiyor. Bu da daha uzun vakit harcamak anlamına geliyor. Tabi günlük şu kadar demek biraz zor fakat 30 dakika ile 7-8 saate kadar uzayabilen bir zaman dilimine ihtiyacım olduğunu söyleyebilirim.

GK3: Cep telefonu.

GK4: Yukarıda belirttiğim gibi evde çok zaman harcamıyorum, eğitim süresince oldukça fazla zaman harcadım, bazen 8 saate yakın ders çalışmak zorunda kaldım bazen 3-4 saat uyumak zorunda kaldım, evde de ofisteki gibi bilgisayarla ve telefonla işlem yapmaktayım.

GK5: Cep telefonu 30 dakika.

GK6: Cep telefonu 10-15 $d k$.

GK7: Genelde telefon uygulamaları üzerinden işlem yapmak kolay olduğu ve internet kullanımının bilgisayara göre daha mobil olduğu için telefonla yapıyorum. Toplu taşımada genelde vaktimin çoğunu yarım saat bir saat onunla harcıyorum.

GK8: Cep telefonu, 2-3 saat harclyorum.

GK10: Cep telefonu gün boyunca.

GK11: Cep telefonu ile alım satım işlemlerimi yapıyorum genelde. Ortalama 2-3 saat harcıyorum.

GK12: Telefon.

GK13: Cep telefonu ile paribu kullanarak yapıyorum.

Bu sorunun sorulmasının temel amacı kripto varlık yatırımcısı çalışanların bu yatırımlarının hayatlarında ne kadar yer aldığını tespit edebilmektir. Ayrıca mesai saatleri ile mesai dışı zamanlarda ne kadar bir zamanın bu yatımları izlemeye ayrıldığının tespiti de yapılmak istenmiştir. Bu sayede, çalışanların işyerinde gerçekleşen sanal kaytarma davranışı süresi ile mesai dışı sürelerinin karşılaştırılması yapılabilecektir. Verilen cevaplardan da anlaşılacağı üzere katılımcıların çoğunun cep telefonlarından yatırımlarının finansal seyrini mesai saatleri dışında da sürdürdükleri anlaşılmaktadır. Bu süreler 10-15 dakika ile 2-3 saat arasında değişmektedir.

\section{S12. Bize işinizden bahseder misiniz? Genelde gün içinde hangi işlerle uğraşmaktasınız? İşiniz yoğun ve yorucu mudur?}

\section{GK1: İ̧̧im çok yoğun değil.}

GK2: Iş̧im yoğun evet. Akademisyen olduğum için iş vaktimi tam olarak tanımlamam mümkün değil. Çoğu zaman evde işle ilgili işyerinden daha fazla vakit geçirdiğim bile olabiliyor. İşyerinde genellikle ders verme ve idari işlerle ilgilendiğim için akademik çalışmaları evde yapmak durumunda kalıyorum. Yanı işim yoğun diyebilirim ama severek yaptığım için yorulmuyorum.

GK3: Genelde araştırma yapmakla meşgulüm. Çok fazla sıkışmamışsam yoğun ya da yorucu olduğu söylenemez. 
GK4: Muhasebe ve denetim işleri çoğunlukla kesinlikle yorucu ve oldukça stresli.

GK5: Işlerim Oldukça yoğun ve yorucudur.

GK6: Bazen.

GK7: Iş̧im şirketimizin gelişiminde nasıl daha iyiye gidebileceğimizi, yeni özellikler nasıl ekleyeceğimiz, sosyal medya yönetimi gibi konuları içeriyor. Yeni bir firma olduğundan yoğun ve yorucu geçiyor.

GK8: Araştırma görevlisiyim, genellikle akademik çalışma yapıyorum. Son dönemlerde işim çok yoğun ve yorucu olmuyor.

GK9: Hayır yorucu değil fırsatım var ama kripto para ile ilgileniyorum. İşim elektrik dağıtım sektörü.

GK10: Rutin memur işleri mutemetlik, yazı işleri, öğrenci işleri, bazı dönemlerde yoğun olmakta.

GK11: ISTKA ve Avrupa Birliği projeleri yazıyoruz ve bu projeler kapsamında yapılacak ihale şartnamelerini ve sözleşme süreçlerini yönetiyorum. Bazı dönemlerde yoğunluğu olan bir iş. Yorucu olduğunu da söyleyebilirim.

GK13: Günlere göre yoğunluk değişmekte.

Bu soruda da temel amaç katılıcıların iş yoğunluğunu tespit etmeye çalışmaktır. Bu sayede yoğun bir mesaisi olan çalışanlarda da sanal kaytarma davranışının olup olmadığı gözlemlenmeye çalışılmıştır. Verilen cevaplardan da anlaşılacağı üzere katılımcılardan bazıları işlerini yoğun bulmazken birçoğu ise yoğun ve yorucu bulmaktadır. İşlerini yoğun ve yorucu bulan bu çalışanların kripto varlıklarla ilgili takiplerinin ise 10. sorudan da anlaşılacağı üzere 30 dakikadan az olmamak koşuluyla günde 4 saate kadar çıktığı anlaşılmaktadır.

\section{SONUÇ VE TARTIŞMA}

Kripto varlık piyasasında bugün itibarıyla en yüksek piyasa değerine sahip Bitcoin başta olmak üzere 5 binden fazla kripto para türü mevcuttur. Her geçen gün finans ve ticari kuruluşlarla birlikte pek çok bankanın da ödeme araçları listesinde olması bu varlıklara olan talebin gelecekte daha da artacağı anlamına gelmektedir (Çetin, 2020). Bu çalışma ile her geçen gün sayısı artan kripto varlık yatırımcılarının mesai saatleri içinde sanal kaytarma davranışı gösterip göstermediğinin tespitine çalışılmıştır. Elde edilen veriler ve yapılan analizler sonucunda ulaşılan bilgileri şu şekilde özetlemek mümkündür.

Demografik verilere göre, gönüllü olan katılımcılar 20 ile 48 yaş aralığındadır. Mesleki durumları ise işçi, memur, akademisyen, mühendis ve mali müşavir gibi farklı meslek gruplarıdır. Ayrıca katılımcıların toplam çalışma süreleri ise 1 yıldan 21 yıla kadar değişkenlik göstermektedir. Bu verilerden hareketle kripto varlık yatırımcılarının yaş, meslek ve toplam çalışma süresi açısından geniş bir yelpazede olduğu sonucuna varılabilir.

Finansal alanlarda yatırım yapmak ve karlı sonuçlar elde edebilmek hiç şüphesiz finansal okuryazarlıkla mümkün olabilmektedir. Kripto varlıklar gibi yeni ve henüz tüm yönleriyle anlaşılamamış bir finansal varlığa yatırım yapmak bu alanla bilgi birikiminin olmasını gerektirebilir. Kripto varlıkları tanımlamalarının istendiği soruya katılımcıların verdiği cevaplar; yatırım aracı, hayali para, dijital para, kaynağı belli olmayan varlık, sanal para ve sayısal veri şeklinde olmuştur. Verilen cevapların kısalığı, birbirinden farklı oluşu ve tam anlamıyla kripto varlıkları açıklayamamış olmasından dolayı araştırmaya katılan gönüllülerin çoğunda kripto varlıklarla ilgili bilgi düzeylerinin sınırlı olduğu sonucuna varılabilir. Kripto varlıklarla ilgili bilgi düzeylerinin az olmasına rağmen katılımcıların büyük çoğunluğu kripto varlıkları geleceğin yatırım araçları içerisinde görmektedir. Ayrıca yüksek riskine rağmen bu varlıkları yüksek getiri elde edilebilecek finansal araçlar olarak düşünmektedirler. Bu alanda yatırımı başkaları için tavsiye edip etmedikleriyle ilgili düşünceleri yatırım yapılması gerektiği şeklindedir.

Araştırmanın bir diğer neticesi katılımcıların çok azının bu piyasalara girmeden evvel bir eğitime ihtiyaç hissetmedikleri sonucudur. Bu bulgu, yüksek risk ihtiva eden bu piyasalarda katılımcıların bazılarının yatırımlarını bir nevi gözü kapalı yaptıkları anlamına gelebilir. Katılımcıların çoğunun fikri ise bu alanda bir eğitimin gerekli olduğu düşüncesidir. Hatta bazılarının cevaplarından eğitimin gerekliliğini yatırım yaptıktan sonra hissettiği anlaşımaktadır. Buradan hareketle kripto varlıklara yatırım yapacak kişilerin eğitim alması gerektiği sonucuna varılabilir.

Katılımcıların sanal kaytarma yapmasını sağlayacak araçların neler olduğunu tespite dönük sorulan soruya verdikleri cevaplardan katılımcıların, kripto varlıklarla ilgili yatırımlarını izlemek için iş yerinin bilgisayarını ve şahsi cep telefonlarını kullandığı anlaşılmıştır. Ayrıca bu cihazlardan ne sıklıkta istifade edildiği diğer bir ifadeyle ne sıklıkta ve sürede sanal kaytarama yaptıklarının tespitine dönük soruya ise katılımcıların çoğunun kripto varlıklarının finansal durumunu öğrenmek, yenisini almak veya satmak için saatlerini harcadıkları şeklindedir. İş yoğunluklarıyla ilgili soruya çoğu katılımcı işlerinin yoğun ve yorucu olduğu şeklinde cevaplamışlardır. Bu 
bulgu, kripto varlık yatırımcılarının iş yerlerinde ve mesai saatlerinde ve üstelik yoğun tempolu zamanlarda bile sanal kaytarma davranışı gösterdiği anlamına gelebilir.

Çalışanların mesai dışında da kripto varlıklarla ilgili takiplerinin devam ettiği verdikleri cevaplardan anlaşılmıştır. Mesai sonrası zamanlarda çalışanların kişisel ihtiyaçlarının dışında dinlenmeye de zaman ayırmaları gerekmektedir. Çünkü yeterince dinlenememiş veya yeterli uykuyu alamamış çalışan bir sonraki gün verimli çalışamaya bilmektedir. Çalışanın verimsizliğine zemin hazırlayan bu takip isteğinin, mesaiyi etkileyecek bir davranış olduğu söylenebilir. Katılımcı cevaplarından bu takipler için uzun saatler ayırabildikleri anlaşılmıştır. Bu durumun bir nevi bağımlılığa (finansal varlık takip bağımlılığı) dönüşme riski göz ardı edilmemelidir.

Sonuç olarak, örgütler üzerinde ciddi etkileri olan sanal kaytarma davranışının öncülleri arasında kripto varlık piyasası takip isteğinin de olduğu anlaşılmıştır. Sanal kaytarmaya neden olan birçok etken tespit edilmiş olmasına rağmen, kripto varlıklarla ilgili takip isteğinin de öncüller arasında olabileceği bulgusu alan yazınına katkı sunacağı düşüncesinden dolayı önemli görülmektedir. Her çalışmanın olduğu gibi bu çalışmanın da bazı kısıtlar ihtiva ettiği bilinmelidir. Öncelikle çalışma nitel bir yöntem belirlenerek yapılmıştır. Bu sebeple sonuçların genellenmesi uygun görülmemektedir. Ayrıca katılımcıların cevaplarında objektif davranmamış olma ihtimali göz ardı edilmemelidir. Kısıtlı zamanda ve bazıları online görüşme ile elde edilen bu çalışmanın daha geniş zamanlarda bir veya birkaç işletmede ve bu alanda oluşturulacak ölçekler sayesinde daha fazla katılımcı ve bağımlılık ekseninde yapılmasının faydalı olacağı düşünülmektedir.

\section{REFERANSLAR}

Akbaba, A. N. B. (2009). Sanal kaytarmanın verimliliğe ve maliyete etkisi: Bir Uygulama. Verimlilik Dergisi, 3, $161-179$.

Aksoy, E., Teker, T., Mazak, M., \& Kocabıyık, T. (2020). Kripto paralar ve fiyat ilişkileri üzerine bir analiz: Toda-Yamamoto nedensellik analizi ile bir inceleme. Süleyman Demirel Üniversitesi Sosyal Bilimler Enstitüsü Dergisi, 37, 110-129.

Alan, H. (2019). Sosyal ağ kullanımı yoğunluğu ve sanal kaytarma davranışları: üniversite öğrencileri üzerine bir inceleme. Çağdaş Yönetim Bilimleri Dergisi, 6(2), 112-129.

Alkış, A. (2018). İslam hukuku açısından bitcoinve kripto para. Kahramanmaraş Sütçü İmam Üniversitesi İktisadi ve İdari Bilimler Fakültesi Dergisi, 8(2), 6990.

Alpago, H. (2018). Bitcoin'den selfcoin'e kripto para. Uluslararası Bilimsel Araştırmalar Dergisi (IBAD), 3(2), 411-428. Https://Doi.Org/10.21733/ibad.419462

Anandarajan, M., \& Simmers, C. A. (Ed.). (2004). Personal web usage in the workplace: a guide to effective human resources management. IGI Global. Https://Doi.Org/10.4018/978-1-59140-148-3

Anandarajan, M., Simmers, C. A., \& D'ovidio, R. (2011). Exploring the underlying structure of personal web usage in the workplace. Cyberpsychology, Behavior and Social Networking, 14(10), 577-583.

Arıkan, N. İ. (2020). An overview of the cryptocurrencies: the theory of money perspective. Malatya Turgut Özal Üniversitesi İşletme ve Yönetim Bilimleri Dergisi, 1(2), 147-165.

Aslan, Ü. A. (2020). Kripto para muhasebesi üzerine yapılan tartışmalar ve finansal raporlama üzerindeki etkileri. Tide Academia Research, 2(2), 257-286.

Ateş, B. A. (2016). Kripto para birimleri, bitcoin ve muhasebesi. Çankırı Karatekin Üniversitesi Sosyal Bilimler Enstitüsü Dergisi, 7(1), 349-366.

Avşar, í. İ., \& Serin, Z. V. (2020). Seçili kripto paralarda kümeleme analizi. Türk Sosyal Bilimler Araştırmaları Dergisi, 5(1), 41-52.

Avunduk, H., \& Aşan, H. (2018). Blokzinciri (Blockchain) teknolojisi ve işletme uygulamaları: genel bir değerlendirme. Dokuz Eylül Üniversitesi İktisadi İdari Bilimler Fakültesi Dergisi, 33(1), 369-384. Https://Doi.Org/10.24988/Deuiibf.2018331746

Babadağ, M. (2018). İşe Yabancılaşmanın Sanal Kaytarma Üzerindeki Etkisi. Balıkesir Üniversitesi Sosyal Bilimler Enstitüsü Dergisi, 21(39), 207-239. Https://Doi.Org/10.31795/Baunsobed.437734

Başkale, H. (2016). Nitel araştırmalarda geçerlik, güvenirlik ve örneklem büyüklüğünün belirlenmesi. Dokuz Eylül Üniversitesi Hemşirelik Fakültesi Elektronik Dergisi, 9(1), 23-28.

Baturay, M. H., \& Toker, S. (2015). An investigation of the impact of demographics on cyberloafing from an educational setting angle. Computers in Human Behavior, 50, 358-366. Https://Doi.Org/10.1016/J.Chb.2015.03.081

Bilgili, F., \& Cengil, M. F. (2019). Bitcoin özelinde kripto paraların ticaret şirketlerine sermaye olarak getirilmesi. Ankara Hacı Bayram Veli Üniversitesi Hukuk Fakültesi Dergisi, 23(3), 3-23. Https://Doi.Org/10.34246/Ahbvuhfd.609020

Blanchard, A. L., \& Henle, C. A. (2008). Correlates of different forms of cyberloafing: the role of norms and external locus of control. Computers in Human Behavior, 24(3), 1067-1084. Https://Doi.Org/10.1016/J.Chb.2007.03.008 
Buğan, M. F. (2021). Bitcoin ve altcoin kripto para piyasalarında finansal balonlar. Akademik Araştırmalar ve Çalışmalar Dergisi (AKAD), 13(24), 165-180. Https://Doi.Org/10.20990/Kilisiibfakademik.880126

Creswell, J. W. (2003). Research Design: Qualitative, Quantitative and Mixed Methods Approaches. California: Sage Publications

Çavuşoğlu, S., \& Palamutçuoğlu, B. T. (2017). İş Tatmininin Sanal Kaytarma Üzerindeki Etkisi. Mehmet Akif Ersoy Üniversitesi Sosyal Bilimler Enstitüsü Dergisi, 9(19), 430-444. Https://Doi.Org/10.20875/Makusobed.289250

Çetin, A. (2020). İslami esaslara uygun kripto para önerisi: islami coin (Iscoin). Finansal Araştırmalar ve Çalışmalar Dergisi, 12(22), 63-89. Https://Doi.Org/10.14784/Marufacd.688429

Çetin, C., \& Akyelli, N. (2020). Sanal kaytarma ve iş doyumu ilişkisi. İzmir Katip Çelebi Üniversitesi İktisadi ve İdari Bilimler Fakültesi Dergisi, 3(1), 41-59.

Çetinkaya, Ş. (2018). Kripto paraların gelişimi ve para piyasalarındaki yerinin swot analizi ile incelenmesi. Uluslararası Ekonomi ve Siyaset Bilimleri Akademik Araştırmalar Dergisi, 2(5), 11-21.

Çetintürk, İ. (2020). Sanal kaytarma ve demografik özellikler: beş yıldızlı konaklama işletmesinde bir uygulama. Anadolu Üniversitesi İktisadi ve İdari Bilimler Fakültesi Dergisi, 21(2), 35-46.

Çınar, O., \& Sıçrar, H. (2019). Sanal kaytarma ve örgütsel bağlıık arasındaki ilişki: Erzurum ilinde bir kamu kurumu örneği. İ̧̧ ve Hayat, 5(10), 119-135.

Çiçek, B. (2020). Organizasyonları aşındıııı unsurlar olarak sosyal dışlanma ve sanal kaytarma ilişkisi ve bu ilişkide etik iklimin rolü. Yönetim ve Ekonomi Araştırmaları Dergisi, 18(2), 198-217. Https://Doi.Org/10.11611/Yead.746192

Demirbilek, N., \& Atila, F. (2021). Üniversite öğrencilerinin perspektifinden sanal kaytarma kavramı. Adıyaman Üniversitesi Sosyal Bilimler Enstitüsü Dergisi, 38, 196-222. Https://Doi.Org/10.14520/Adyusbd.922639

Garrett, R. K., \& Danziger, J. N. (2008). On cyberslacking: workplace status and personal internet use at work. Cyberpsychology \& Behavior, 11(3), 287292. Https://Doi.Org/10.1089/Cpb.2007.0146

Güğerçin, U., \& Sığırcıkoğlu, E. B. (2019). Rol belirsizliği ve sanal kaytarma: görgül bir araştırma. Akademik Araştırmalar ve Çalışmalar Dergisi (AKAD), 11(20), 152-161. Https://Doi.Org/10.20990/Kilisiibfakademik.532421

Gültekin, Y., Özdemir, F. S., \& Varici, İ. (2019). Kripto para birimlerinin piyasa değerlerindeki değişimlerin analizi. Yönetim ve Ekonomi Dergisi, 26(2), 677688. Https://Doi.Org/10.18657/Yonveek.448639

Holloway, I., \& Wheeler, S. (1996). Qualitative Research For Nurses. Oxford: Blackwell Science Ltd.

Hasırcı, I., \& Örücü, E. (2020). Örgütsel sinizmin sanal kaytarma davranışı üzerindeki etkisinde çalışanların eğitim düzeylerinin düzenleyici rolü. Yönetim ve Ekonomi Araştırmaları Dergisi, 18(4), 285-303. Https://Doi.Org/10.11611/Yead.680513

Jia, H., Jia, R., \& Karau, S. (2013). Cyberloafing And personality: the impact of the big five traits and workplace situational factors. Journal of Leadership \& Organizational Studies, 20(3), 358-365

Johnson, P. R. Ve Indvik, J. (2003). The Organizational Benefits of Reducing Cyberslacking in The Workplace. in Allied Academies International Conference. Academy of Organizational Culture, Communications and Conflict. Proceedings, 8(2), 53-58. Jordan Whitney Enterprises, Inc.

Kaplanhan, F. (2018). Kripto paranın türk mevzuatı açısından değerlendirilmesi “bitcoin örneği”. Vergi Sorunları Dergisi, 353, 105-123.

Karaca, A., \& Karaca, B. (2019). Sağlık çalışanlarının sanal kaytarma davranışları ile örgütsel özdeşleşme düzeyleri arasındaki ilişkinin incelenmesi: bir kamu hastanesi örneği. Ankara Sağlık Hizmetleri Dergisi, 18(1), 27-39.

Karataş, A., \& Avci, S. (2017). Kamu kurumlarında sanal kaytarma olgusunun değerlendirilmesi. Süleyman Demirel Üniversitesi iktisadi ve İdari Bilimler Fakültesi Dergisi, 22, 2321-2346.

Kim, S. J., \& Byrne, S. (2011). Conceptualizing personal web usage in work contexts: a preliminary framework. Computers in Human Behavior, 27(6), 22712283. Https://Doi.Org/10.1016/J.Chb.2011.07.006

Nakamoto, S. (2008). Bitcoin: a peer-to-peer electronic cash system. Decentralized Business Review, 1-9.

Nastasi, B. (2015). Study notes: qualitative research: sampling ve sample size considerations. Erişim: 03.08.2021.

$\mathrm{Http}: / /$ Webcache.Googleusercontent.Com/Search?Q=Cache:Qn6-

7ud2nsgj:Https://My.Laureate.Net/Faculty/Docs/Faculty\%2520documents/Qualit_Res_SSmpl_Size_Consid.Doc+Vecd=1vehl=Envect=Clnkvegl=Tr

Mills, J. E., Hu, B., Beldona, S., \& Clay, J. (2001). Cyberslacking! a liability Issue for wired workplaces. Cornell Hotel and Restaurant Administration Quarterly, 42(5), 34-47.

Öztürk, U. C. (2015). Bağlantıda kalmak ya da kalmamak işte tüm korku bu: internetsiz kalma korkusu ve örgütsel yansımaları. Journal of International Social Research, 8(37), 629-638.

Örücü, E., \& Özüdoğru, M. (2018). Örgütsel güven ile sanal kaytarma davranışları arasındaki ilişkinin belirlenmesine yönelik bir çalışma. Adnan Menderes 
Üniversitesi Sosyal Bilimler Enstitüsü Dergisi, 5(3), 66-80. Https://Doi.Org/10.30803/Adusobed.407273

Örücü, E., \& Yıldız, H. (2014). The personal Internet and technology usage at the workplace: cyberslacking. Ege Academic Review, 14(1), 99-114. Özdemir, G. (2021). Kripto paraların eşya niteliği. Süleyman Demirel Üniversitesi Hukuk Fakültesi Dergisi, 11(1), 289-306. Https://Doi.Org/10.52273/Sduhfd..938420

Özkan, S., \& Erbay, E. Ö. (2021). Örgüt ikliminin çalışanların sanal kaytarma davranışları üzerindeki etkisi. Sakarya Üniversitesi İ̧̧letme Enstitüsü Dergisi, Erken Görünüm, 145-153. Https://Doi.Org/10.47542/Sauied.878519

Özüdoğru, M., \& Yıldırım, Y. T. (2020). Sanal kaytarma ve iş gören performansı ilişkisinde iş stresinin düzenleyici etkisinin incelenmesi: sağılık sektöründe bir araştırma. Afyon Kocatepe Üniversitesi Sosyal Bilimler Dergisi, 22(2), 467-490. Https://Doi.Org/10.32709/Akusosbil.532359

Piotrowski, C. (2012). Cyberloafing: a content analysis of the emerging literature. Journal of Instructional Psychology, 39( 3-4), 259-262

Prasad, Smrithi, Lim, Vivien K.G., Chen, Don J.Q.,(2010). Self-regulation, Individual characteristics and cyberloafing. PACIS 2010 Proceedings. $159-164$.

Robinson, S. L., \& Bennett, R. J. (1995). A typology of deviant workplace behaviors: a multidimensional scaling study. Academy of Management Journal, 38(2), 555-572. Https://Doi.Org/10.5465/256693

Sadıç, E., Eğilmez, Ö., \& Haşit, G. (2020). Üniversite çalışanları bağlamında sanal kaytarma ve örgütsel vatandaşlık davranışı üzerine bir inceleme. Bilecik Şeyh Edebali Üniversitesi Sosyal Bilimler Dergisi, 5(2), 234-256. Https://Doi.Org/10.33905/Bseusbed.777522

Seçilmiş, C., \& Yılmaz, B. (2018). Seyahat acentesi çalışanlarının sanal kaytarma davranışları ve iş motivasyonu arasındaki ilişkilerin incelenmesi. Kesit Akademi Dergisi, 17, 20-37.

Semerci, A. B., Ergeneli, A., \& Yilmaz, Z. (2021). İşyeri Yalnızlı̆ının iki yüzü: sanal kaytarma ve yenilikçi iş performansı. Hacettepe Üniversitesi iktisadi ve İdari Bilimler Fakültesi Dergisi, 39(1), 133-147. Https://Doi.Org/10.17065/Huniibf.691769

Şahin, M. (2019). Kripto para yeni bir vergi sığınağı mı? Bilişim teknolojilerindeki gelişmeler kapsamında bir değerlendirme. Pamukkale Üniversitesi Sosyal Bilimler Enstitüsü Dergisi, 34, 169-181. Https://Doi.Org/10.30794/Pausbed.421510

Şahin, O. N. (2018). TMS \& TFRS ışı̆̆ında muhasebe, vergi ve denetim açısından bitcoin ve diğer kripto para birimleri. Muhasebe Bilim Dünyası Dergisi, 20(4), 898-923. Https://Doi.Org/10.31460/Mbdd.401314

Şenbayram, E. A. (2019). Paranın geldiği uç nokta: Bitcoin. Econharran, 3(4), 72-92.

Streubert, H. J., \& Carpenter, D. R. (2011). Qualitative Research In Nursing. (5th Ed.). Philadelphia: Lippincott Williams \& Wilkins.

Turan, Z. (2018). Kripto paralar, bitcoin, blockchain, petro gold, dijital para ve kullanım alanları. Ömer Halisdemir Üniversitesi İktisadi ve İdari Bilimler Fakültesi Dergisi, 11(3), 1-5. Https://Doi.Org/10.25287/Ohuiibf.431283

Tutar, H., \& Güler, S. (2020). Kamu kurumlarında sanal aylaklık sorunu konusunda yönetici görüşleri: bir durum çalışması. Ankara Hacı Bayram Veli Üniversitesi İktisadi ve İdari Bilimler Fakültesi Dergisi, 22(2), 352-380.

Uçkun, N., \& Dal, L. (2021). Kripto para yatırımcılarında finansal risk toleransı. Muhasebe ve Finansman Dergisi, 89, 155-170. Https://Doi.Org/10.25095/Mufad.852118

Ugrin, J. C., Pearson, J. M., \& Odom, M. D. (2008). Profiling cyber-slackers in the workplace: demographic, cultural, and workplace factors. Journal of Internet Commerce, 6(3), 75-89. Https://Doi.Org/10.1300/J179v06n03_04

Van Doorn, O. N. (2011). Cyberloafing: A Multi-Dimensional Construct Placed in A Theoretical Framework. Unpublished Master Thesis, Department Industrial Engineering And Innovation Sciences Eindhoven University of Technology, Eindhoven: Netherlands.

Yalçın, S. (2019). Kripto değişim araçlarının muhasebeleştirilmesi. Muhasebe ve Finansman Dergisi, 81, 101-120. Https://Doi.Org/10.25095/Mufad.510596

Yıldırım, A., \& Şimşek, H. (2006). Sosyal Bilimlerde Nitel Araştırma Yöntemleri. Ankara: Seçkin Yayıncılık

Yıldırım, F. (2018a). Tükenmişlik düzeyinin sanal kaytarma davranışına etkisinde iş doyumunun aracılık rolü. Gazi Üniversitesi Sosyal Bilimler Dergisi, 5(13), 302-313.

Yıldırım, F. (2018b). Kripto paralar, blok zinciri teknolojisi ve uluslararası ilişkilere muhtemel etkileri. Medeniyet Araştırmaları Dergisi, 2(4), 81-97.

Yıldız, H., Yıldız, B., \& Ateş, H. (2016). Sanal kaytarma davranışlarının sergilenmesinde örgütsel adalet algısının rolü var mıdır? Bilgi Ekonomisi ve Yönetimi Dergisi, 10(2), 0-0.

Yılmaz, Y. (2007). Kriptoloji uygulamalarında hukuki boyut. Marmara Üniversitesi Hukuk Fakültesi Hukuk Araştırmaları Dergisi, 13(1-2), 137-147. 